\title{
Emission Constraint Optimal Power Flow using Differential Evolution
}

\author{
C.N. Ravi \\ Research Scholar \\ Sathyabama University \\ Chennai, Tamil Nadu, India
}

\author{
C. Christober Asir Rajan, PhD. \\ Associate Professor, Dept. of EEE, Pondicherry \\ Engineering College, Pondicherry, India
}

\begin{abstract}
Objective of the power systems firm is to achieve the maximum profit and customer goodwill by providing reliable and quality power supply. This power system operation problem is solved by Optimal Power Flow (OPF). It gives requirement of operating states which satisfy the objective of the firm. Thermal power plants are the main source of power generation. Fuel cost of these power plants has to minimize for better profit at the same time it should satisfy system load demand, real, reactive power limit, voltage limit, power transmission limit and other limitations. For generation cost minimization Economic Load Dispatch (ELD) and Optimal Power Flow (OPF) was developed. When cost is the single objective, the power generation may pollute the environment. Thermal electric power could not be generated without pollution but this pollution can be reduced for the sake of good and healthy atmospheric condition. Differential Evolution (DE) algorithm is used in this paper to solve Emission Constraint Optimal Power Flow problem. Standard IEEE 30 bus, power system having 6 thermal power plants, is considered to validate the simulation.
\end{abstract}

\section{Keywords}

Deferential Evolution, Optimal Power Flow, emission dispatch, Newton Raphson power flow.

\section{INTRODUCTION}

Development of country and population growth needs more and more electric power at a reasonable price and pollution less power. But this electric power demand is supplied mainly by thermal power plants, which produce harmful gases like Sulfur Oxides SOx, Nitrogen Oxides NOx and Cox [1], [2]. General OPF solution aims on minimum generating cost and emission is not considered. Emission Constraint Optimal Power Flow problem aims to reduce emission level as well as generating or fuel cost. Environmental economic dispatch (EED) problem [3] was developed to find minimum generating cost and minimum emission, these problems are not consider the transformer tap position which is one of the main control variable in OPF [7], [12].

Rainer Storn R and Kenneth Price proposed novel heuristic algorithm called Differential Evolution (DE) in1997 [16], to fulfill the requirement the optimization technique. DE algorithm is intended for minimization problem which may non-differential, non-linear and multimodal. DE is Easy to implement and it has good convergence for global optimization. Suganthan P. N explains different mutation and crossover methods in DE [8].

Yong Wang, and Zixing Cai describes multi objective DE to constraint optimization problem [15]. DE is used to solve OPF [4], [10] but emission is not considered in the earlier literature. DE is also used to solve EED [5], [11] but important parameter of voltage magnitude and transformers are not considered.

Combined Economic Emission Dispatch (CEED) solved which consider only real power balance equality constraint [6]. Gnanadass R, and Narayana Prasad Padhy used Evolutionary Programming (EP) to solve CEED and a novel concept of modified price penalty factor [9] for better optimum solution. Like DE many heuristic algorithms like Artificial Bee Colony [13], Particle Swarm Optimization (PSO) [14], Genetic Algorithm [12], [18], etc.., are used to solve EED and OPF problems separately. This paper presents a problem which combines OPF and emission. To solve this control variables of Generators real power generation except slack bus, generator bus voltage magnitude and transformer tap position are considered. To calculate generation cost and emission quadratic cost function and emission function are considered in the paper.

\section{DIFFERENTIAL EVOLUTION}

The ability of DE is to optimize nonlinear, non-continuous and non-differential real world problems. Compare to other population based meta heuristic algorithms, DE emphasis on Mutation than Recombination or Crossover. It mutate vector with a help of randomly selected a pair of vector in the same population. The mutation guides the vector towards the global optimum. The distribution of the difference between randomly sampled vectors is determined by the distribution of these vectors. This enables DE function robustly and more as a generic global optimizer. DE works on population of vectors, where vector is a group of decision variables. Selection of decision variable is based on their impact on the problem to be optimized. These decision variables need to be encoded and set of initial values are chosen from the solution space. By mutation and recombination new vectors are created. The selection process selects the best vectors based on the selection criterion.

\subsection{Encoding}

Encoding is the process of converting group of decision variables into vector and objective function into fitness function. Ability of DE is to operate on floating point and mixed integer makes ease of encoding decision variables into vectors. Number of decision variables is the size of the vector and each vector gives one solution from the solution space for the problem defined

\subsection{Mutation}

The objective of mutation is to enable search diversity in the parameter space as well as to direct the existing vectors with suitable amount of parameter variation in a way that will lead to better results at a suitable time. It keeps the search robust and explores new areas in the search domain. There are 4 types of mutation [8]. 
$\mathrm{DE} / \mathrm{rand} / 1 /$ bin $-\mathrm{Yi}=\mathrm{Xr} 1+\mathrm{F}^{*}(\mathrm{Xr} 2-\mathrm{Xr} 3)$

$\mathrm{DE} / \mathrm{rand} / 2 / \mathrm{bin}-\mathrm{Yi}=\mathrm{Xr} 1+\mathrm{F}^{*}(\mathrm{Xr} 2-\mathrm{Xr} 3)+\mathrm{F}^{*}(\mathrm{Xr} 4-\mathrm{Xr} 5)$

$\mathrm{DE} / \mathrm{best} / 1 / \mathrm{bin}-\mathrm{Yi}=\mathrm{Xbest}+\mathrm{F}^{*}(\mathrm{Xr} 1-\mathrm{Xr} 2)$

$\mathrm{DE} /$ best $/ 2 /$ bin $-\mathrm{Yi}=\mathrm{Xbest}+\mathrm{F}^{*}(\mathrm{Xr} 1-\mathrm{Xr} 2)+\mathrm{F}^{*}(\mathrm{Xr} 3-\mathrm{Xr} 4)$

$\mathrm{r} 1 \neq \mathrm{r} 2 \neq \mathrm{r} 3 \neq \mathrm{r} 4 \neq \mathrm{r} 5$ are randomly selected

\subsection{Crossover}

Crossover aims at reinforcing prior successes by generating child individuals out of existing individuals or vectors parameters. The cross over constant is used to determine if the newly generated individual is to be recombined. There are two types of cross over namely Binomial and Exponential [8]. To form trail vector in binomial method a random number is generated, if this value is less than the cross over constant then mutated vector variable is considered otherwise target vector variable is considered.

\subsection{Selection}

Fitness of the trail vector and the target vector is compared and the vector which has minimum objective value is selected for the next generation. This keeps the population size constant for all the generation.

\section{PROBLEM FORMULATION}

Optimal Power Flow is a minimization problem, needs to minimize generation cost. In this work quadratic cost equation is considered as given below

$C_{t}=\sum_{i=1}^{n g} \alpha_{i}+\beta_{i} P_{G i}+\gamma_{i} P_{G i}^{2} \quad \$ / \mathrm{Hr}$

Emission of harmful gases is calculated in ton/ $\mathrm{Hr}$ using a quadratic equation as given below

$$
E\left(P_{G}\right)=\sum_{i=1}^{n g} 10^{-2}\left(a_{i}+b_{i} P_{G i}+c_{i} P_{G i}^{2}\right)+d_{i} \exp \left(e_{i} P_{G i}\right)
$$

Emission constraint OPF is needs to minimize emission and generating cost. The objective function is

$$
\text { Min } \mathrm{F}(\mathrm{PG})=\mathrm{Ct}+\mathrm{h} * \mathrm{E}(\mathrm{PG}) \$ / \text { hour }
$$

Where,

$\mathrm{F}\left(\mathrm{P}_{\mathrm{G}}\right)=$ Emission constraint OPF objective function in $\$ /$ hour

$\mathrm{Ct}=$ Total generation cost in $\$ /$ hour

$\mathrm{E}\left(\mathrm{P}_{\mathrm{G}}\right)=$ Total emission in ton/hour

$\alpha, \beta, \gamma=$ Cost coefficients of the generator

$\mathrm{a}, \mathrm{b}, \mathrm{c}, \mathrm{d}, \mathrm{e}=$ Emission coefficients of the generator

$\mathrm{P}_{\mathrm{Gi}}, \mathrm{Q}_{\mathrm{Gi}}=$ Active and Reactive power of $\mathrm{i}^{\mathrm{th}}$ generator

$\mathrm{ng}=$ Total number of generators

$\mathrm{h}=$ price penalty factor in $\$ /$ ton

\section{Subject To:}

Equality constraints

$$
\sum_{i=1}^{n g} P_{G i}=P_{D}+P_{L}
$$

$\sum_{i=1}^{n g} Q_{G i}=Q_{D}+Q_{L}$

Inequality constraints

$$
\begin{array}{ll}
V_{i(\min )} \leq V_{i} \leq V_{i(\max )} & \text { for } \mathrm{i}=1 \text { to Nbus } \\
P_{G i(\min )} \leq P_{G i} \leq P_{G i(\max )} & \text { for } \mathrm{i}=1 \text { to } n g \\
Q_{G i(\min )} \leq Q_{G i} \leq Q_{G i(\max )} & \text { for } \mathrm{i}=1 \text { to } \mathrm{ng}
\end{array}
$$

$$
t_{i(\min )} \leq t_{i} \leq t_{i(\max )} \quad \text { for } \mathrm{i}=1 \text { to Ntrans }
$$

Where,

$\mathrm{P}_{\mathrm{Gi}}, \mathrm{Q}_{\mathrm{Gi}}=$ Active and Reactive generation of $\mathrm{i}^{\text {th }}$ generator

$\mathrm{P}_{\mathrm{D}}, \mathrm{Q}_{\mathrm{D}}=$ Active and Reactive demand

$\mathrm{P}_{\mathrm{L}}, \mathrm{Q}_{\mathrm{L}}=$ Active and Reactive loss

$\mathrm{V}_{\mathrm{i}}=$ Voltage at $\mathrm{i}^{\text {th }}$ bus

Nbus $=$ Number of buses

$\mathrm{ng}=$ Number of generators

Ntrans $=$ Number of transformers

\section{DE APPROACH}

Control variables are used to formulate a vector, in the specified problem real power generation of all generators except slack bus generator, voltage magnitude of all generators, transformer tap positions are considered. As test case IEEE 30 bus considered, which has 6 generators and 4 transformers gives 5 real power (except slack bus), 6 generator voltages and 4 transformers (total 15 variables) are considered as control variables. Population size or number of vectors considered is 66 for the simulation.

Vector, $\quad \mathrm{Y}=\left[\mathrm{X}_{1}, \mathrm{X}_{2} \ldots \mathrm{X}_{15}\right]$

Population, $\mathrm{P}=\left[\mathrm{Y}_{1}, \mathrm{Y}_{2} \ldots \mathrm{Y}_{66}\right]$

\subsection{Initialization}

Initialization is the process of generating vectors in a population within its minimum and maximum limits using the equation given below

$\mathrm{Y}^{(0)}=\mathrm{Y}^{\mathrm{min}}+\eta\left(\mathrm{Y}^{\mathrm{max}}-\mathrm{Y}^{\mathrm{min}}\right)$

In the above equation $\mathrm{Y}^{\min }$ and $\mathrm{Y}^{\max }$ is minimum and maximum limit of decision variables, $\eta$ is a random number between 0 and 1 .

\subsection{Mutation}

Mutation is the main process in DE, weighted differences of randomly chosen vectors other than target vector is used to mutate the target vector. Target vector is a vector which is considered for the mutation. Mutation rule used in the work is given below

$\mathrm{Y}_{\mathrm{i}}=\mathrm{Y}_{\text {best }}+\mathrm{F}^{*}\left(\mathrm{Y}_{\mathrm{r} 1}-\mathrm{Y}_{\mathrm{r} 2}\right)+\mathrm{F}^{*}\left(\mathrm{Y}_{\mathrm{r} 3}-\mathrm{Y}_{\mathrm{r} 4}\right)$

and $\mathrm{r} 1 \neq \mathrm{r} 2 \neq \mathrm{r} 3 \neq \mathrm{r} 4 \neq$ best

In the equation (13), $\mathrm{Y}_{\mathrm{i}}$ is the target vector; $\mathrm{Y}_{\text {best }}$ is the vector which gives minimum value among all the vectors in the current generation. $\mathrm{Y}_{\mathrm{r} 1}, \mathrm{Y}_{\mathrm{r} 2}, \mathrm{Y}_{\mathrm{r} 3}$ and $\mathrm{Y}_{\mathrm{r} 4}$ are randomly chosen vector in the population of current generation. $\mathrm{F}$ is scaling factor, which may have value between 0 and 1 .

\subsection{Crossover}

Crossover is the process of generating trail vector from mutated and target vector. Trail vector is a combination of target and mutated vector. For each control variable in a vector a random number between 0 and 1 is generated if it is less than crossover constant chosen, then control variable from mutated vector is selected otherwise it is selected from target vector to form a trail vector as given below.

$X_{\text {trail }}^{(G)}=\left\{\begin{array}{l}X_{\text {mutate }}^{(G)} \rightarrow \text { if }\left(\eta \leq C_{R}\right) \\ X_{t \text { arg } \text { et }}^{(G)} \ldots \ldots \text {..... atherwise }\end{array}\right.$

In above equation $\mathrm{X}$ is a control variable, superscript $\mathrm{G}$ is the generation number, $\eta$ is a random number between 0 and 1 . 


\subsection{Selection}

For the control variables in target vector and trail vector Newton Raphson power flow is executed to satisfy equality constraints (4) and (5), know the dependent variables value like load bus voltages, reactive power generation and to evaluate objective function given by equation (3). If the objective function value of trail vector is less than the target vector, then trail vector is consider to next generation otherwise target vector is considered to next generation.

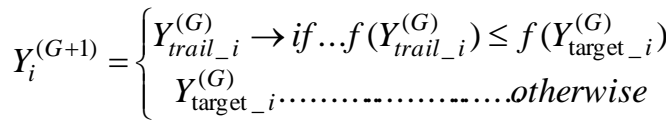

for $\mathrm{i}=1$ to No. of population

In the above equation $\mathrm{Y}$ is a vector, superscript $\mathrm{G}$ represents generation number and $\mathrm{f}(\mathrm{Y})$ is the objective function value for the vector $\mathrm{Y}$.

These processes mutation, crossover and selection are repeated for generation to generation till the stopping criterion

\section{SIMULATION RESULTS}

This emission constraint OPF is implemented in MATLAB, $\mathrm{R} 2010 \mathrm{a}-32$ bit version. Intel Core-2, CPU at $2.00 \mathrm{GHz}$ processor is used for the installation and execution. Parameters of DE are considered as, number of decision variable (D) is 15 , population size (NP) is 66 , scaling factor value $(\mathrm{F}) 0.9$ and crossover constant $(\mathrm{CR})$ value 0.3 .

Table 1, provide values of maximum and minimum generation of generators and cost coefficient. Table 2 gives emission coefficient for the system. Minimum and maximum limit for all bus voltages is taken as $0.95 \mathrm{pu}$ and $1.05 \mathrm{pu}$. Minimum and maximum limits of transfer tap positions are $0.9 \mathrm{pu}$ and $1.1 \mathrm{pu}$. Real and reactive power load for the system is 283.4 MW and 126.2 MVAR respectively. Price penalty factor is taken as $1000 \$ /$ ton

Table 1. Generator Limits \& Cost Coefficients

\begin{tabular}{|c|c|c|c|c|c|c|c|}
\hline \multirow{2}{*}{$\begin{array}{c}\text { Gen } \\
\text { No }\end{array}$} & $\begin{array}{c}\text { Real Power } \\
\text { Limit } \\
(M W)\end{array}$ & \multicolumn{2}{|c|}{$\begin{array}{c}\text { Reactive } \\
\text { Power } \\
\text { Limit (Mvar) }\end{array}$} & \multicolumn{3}{|c|}{$\begin{array}{c}\text { Cost } \\
\text { Coefficients }\end{array}$} \\
\cline { 2 - 8 } & Min & Max & Min & Max & $\alpha$ & $\beta$ & $\gamma$ \\
\hline 1 & 5 & 50 & -40 & 50 & 10 & 200 & 100 \\
\hline 2 & 5 & 60 & -40 & 50 & 10 & 150 & 120 \\
\hline 3 & 5 & 100 & -40 & 40 & 20 & 180 & 40 \\
\hline 4 & 5 & 120 & -10 & 40 & 10 & 100 & 60 \\
\hline 5 & 5 & 100 & -6 & 24 & 20 & 180 & 40 \\
\hline 6 & 5 & 60 & -6 & 24 & 10 & 150 & 100 \\
\hline
\end{tabular}

Table 2. Generator Emission Coefficients

\begin{tabular}{|c|c|c|c|c|c|}
\hline \multirow{2}{*}{ Gen. No } & \multicolumn{5}{|c|}{ Emission Coefficients } \\
\cline { 2 - 6 } & $\mathbf{a}$ & $\mathbf{b}$ & $\mathbf{c}$ & $\mathbf{d}$ & e \\
\hline 1 & 4.091 & -5.554 & 6.490 & $2 \mathrm{e}-4$ & 2.857 \\
\hline 2 & 2.543 & -6.047 & 5.638 & $5 \mathrm{e}-4$ & 3.333 \\
\hline 3 & 4.258 & -5.094 & 4.586 & $1 \mathrm{e}-6$ & 8.000 \\
\hline 4 & 5.426 & -3.550 & 3.380 & $2 \mathrm{e}-3$ & 2.000 \\
\hline 5 & 4.258 & -5.094 & 4.586 & $1 \mathrm{e}-6$ & 8.000 \\
\hline 6 & 6.131 & -5.555 & 5.151 & $1 \mathrm{e}-5$ & 6.667 \\
\hline
\end{tabular}

Output of simulation is given in table 3. The result of proposed method is compared with earlier literature results. It is observed that proposed method fuel cost $612.02 \$ / \mathrm{Hr}$ is less than other methods and emission 0.20545 is less than other methods except MODE [5] but in MODE method generating cost higher, so proposed method may provide better solution to emission constraint $\mathrm{OPF}$

Table 3. Comparison of Generation Cost and Emission

\begin{tabular}{|c|c|c|c|c|}
\hline $\begin{array}{c}\text { Real Power } \\
\text { Gen. (MW) }\end{array}$ & $\begin{array}{c}\text { SPEA } \\
{[\mathbf{1}]}\end{array}$ & $\begin{array}{c}\text { MODE } \\
{[\mathbf{5}]}\end{array}$ & $\begin{array}{c}\text { PSO } \\
{[\mathbf{1 4}]}\end{array}$ & $\begin{array}{c}\text { Proposed } \\
\text { Method }\end{array}$ \\
\hline $\mathbf{P}_{\mathbf{G} 1}$ & 29.96 & 25.2758 & 17.613 & 18.7185 \\
\hline $\mathbf{P}_{\mathbf{G} 2}$ & 44.74 & 40.6968 & 28.188 & 38.785 \\
\hline $\mathbf{P}_{\mathbf{G} 3}$ & 73.27 & 56.1153 & 54.079 & 54.0016 \\
\hline $\mathbf{P}_{\mathbf{G} 4}$ & 72.84 & 66.9946 & 76.963 & 75.8716 \\
\hline $\mathbf{P}_{\mathbf{G} 5}$ & 11.97 & 53.6240 & 65.019 & 55.4841 \\
\hline $\mathbf{P}_{\mathbf{G 6}}$ & 53.64 & 43.6732 & 44.569 & 43.1681 \\
\hline Fuel Cost \$/hr & 629.394 & 617.9962 & 612.35 & $\mathbf{6 1 2 . 0 2}$ \\
\hline $\begin{array}{c}\text { Emission } \\
\text { ton/hr }\end{array}$ & 0.21143 & 0.2009 & 0.20842 & $\mathbf{0 . 2 0 5 4 5}$ \\
\hline \multicolumn{4}{|l}{} \\
\hline
\end{tabular}

Convergence curve of DE approach to emission constraint OPF is given in Fig 1. In the simulation 200 iterations is taken as stopping criterion, so convergence is given for 200 iterations. Solution is converged around $58^{\text {th }}$ iteration shows generation cost is settle down to $612.02 \$ / \mathrm{Hr}$ and corresponding emission level is freeze to $0.20545 \mathrm{ton} / \mathrm{hr}$ is also clear from the convergence curve.
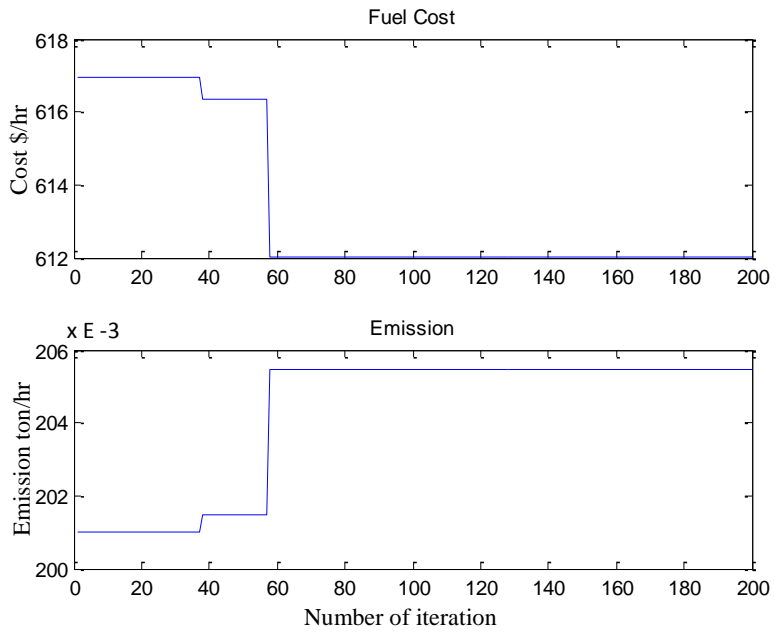

Fig 1: Convergence curve

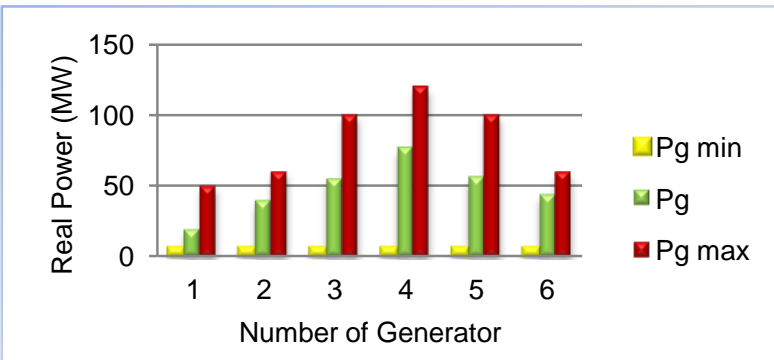

Fig 2: Real Power Generation

Fig 2, shows the real power generation of all 6 generators. These real power generation is substitute in objective function to get best generation cost and emission. It is clear from the fig 2 the generation is within its limits. 


\section{CONCLUSION}

Optimal Power Flow (OPF) is a nonlinear nonconvex problem, conventional techniques like NR method is inferior to find best (global) optimal value. Meta heuristic techniques are superior in finding global optimal value. In this research paper one such meta heuristic technique, DE used to solve OPF. Prime importance of OPF is to reduce the generating cost, emission level and to satisfy all equality and inequality constraints. Equality constraint of power balance equation is satisfied, by NR method power flow used is a subset module in the algorithm. The results also guarantees control variables and dependent variables are within their limits. Test case IEEE 30 bus power system considered for demonstration. Results of proposed DE algorithm are compared with other popular algorithms in the literatures. From comparison it is clear the proposed $\mathrm{DE}$ algorithm provides the best solution for emission constraint OPF.

\section{REFERENCES}

[1] Abido M.A, 2003. "Environmental/Economic Power Dispatch using Multiobjective Evolutionary Algorithms ", IEEE Transactions on Power Systems, Vol. 18, No. 4, (November 2003), 1529 - 1537.

[2] Abido M.A, 2003. "A novel multiobjective evolutionary algorithm for environmental/economic power dispatch", Electric Power Systems Research 65, 71-81.

[3] Abido M.A, 2006. "Multiobjective Evolutionary Algorithms for Electric Power Dispatch Problem", IEEE Transactions on Evolutionary Computation, Vol. 10, No. 3, (June 2006), 315 - 329.

[4] Abido M.A, and Al-Ali N.A, "Multi-Objective Differential Evolution for Optimal Power Flow", conference POWERENG 2009, Lisbon, Portugal, pp. 101 - 106, March 18 - 20, 2009.

[5] Spea S.R, Abou El Ela A.A, Abido M.A, 2010. "Multiobjective Differential Evolution Algorithm for Environmental-Economic Power Dispatch Problem", IEEE International Energy Conference, pp.841 - 846

[6] Anurag Gupta, Swarnkar K.K, Dr. Wadhwani S, Dr. Wadhwani A.K, 2012. "Combined Economic Emission Dispatch Problem of Thermal Generating Units using Particle Swarm Optimization", International Journal of Scientific and Research Publications, Vol.2, Issue 7, (July 2012), $1-7$.

[7] Alsac O, and Stott B, 1974. "Optimal load flow with steady state security”, IEEE Trans. Power Apparat. Syst., vol. PAS-93, 745-751.
[8] Suganthan P.N, Tutorial on Differential Evolution, available at http://www.ntu.edu.sg/home/epnsugan

[9] Venkatesh P, Gnanadass R, and Narayana Prasad Padhy, 2003. "Comparison and Application of Evolutionary Programming Techniques to Combined Economic Emission Dispatch With Line Flow Constraints", IEEE Transactions on power systems, Vol. 18, No. 2, (may 2003), $688-697$.

[10] Vaisakh K, Srinivas L.R, 2008. "Differential Evolution Approach for Optimal Power Flow Solution", Journal of Theoretical and Applied Information Technology, 261268.

[11] Mandal K.K, Chakraborty N, 2008. "Differential Evolution based Environmentally Constrained Economic Dispatch", INDICON 2008. Annual IEEE conference, $471-476$.

[12] C.N. Ravi, Dr. C. Christober Asir Rajan, 2012. "Optimal power flow solutions using constraint Genetic Algorithm", National Journal on Advances in Computing and Management, Sathyabama University, Vol. 3, No.1, (April 2012), 48 - 54.

[13] Gopalakrishnan R, and Dr. Krishnan A, 2012 "Intelligence Technique To Solve Combined Economic And Emission Dispatch", Proceedings of the International Conference on Pattern Recognition, Informatics and Medical Engineering, 347 - 352.

[14] Hemamalini S, and Sishaj P Simon, 2008. "Emission Constrained Economic Dispatch with Valve-Point Effect using Particle Swarm Optimization" IEEE Region 10 conference - TENCON 2008, 1-6.

[15] Yong Wang and Zixing Cai, 2012. "Combining Multiobjective Optimization with Differential Evolution to Solve Constrained Optimization Problems", IEEE Trans. on Evolutionary Computation, Vol. 16, No. 1, (Feburary 2012), 117 - 134

[16] R. Storn and K. Price, 1997. "Differential evolution - a simple and efficient heuristic for global optimization over continuous spaces", Journal of Global Optimization vol. $11,341-359$.

[17] http://www.ee.washington.edu

[18] C. Christober Asir Rajan, 2010. "Genetic Algorithm Based Simulated Annealing Method for Solving Unit Commitment Problem in Utility System", Transmission and Distribution Conference and Exposition, 2010 IEEE PES, 1-6. 